\title{
Alteration of complement hemolytic activity in different trauma and sepsis models
}

This article was published in the following Dove Press journal:

Journal of Inflammation Research

25 July 2012

Number of times this article has been viewed

\author{
Christian Ehrnthaller' \\ Umme Amara ${ }^{1}$ \\ Sebastian Weckbach ' \\ Miriam Kalbitz' \\ Markus Huber-Lang ' \\ Soheyl Bahrami ${ }^{2}$ \\ 'Department of Traumatology, Hand, \\ Plastic, and Reconstructive Surgery, \\ Center of Surgery, University \\ of Ulm, Germany; ${ }^{2}$ Ludwig Boltzmann \\ Institute for Experimental and Clinical \\ Traumatology, Vienna, Austria
}

Correspondence: Christian Ehrnthaller Department of Traumatology, Hand, Plastic, and Reconstructive Surgery, University of Ulm, Albert-Einstein-Allee 23, 8908I Ulm, Germany

Tel +49-73I-500-5455 I

Fax +49-73I-500-54502

Email christian.ehrnthaller@uniklinik-ulm.de

\begin{abstract}
Complement activation is involved in various diseases in which innate immunity plays a crucial role. However, its pathophysiological relevance is not clearly understood. Experimental models have been widely used to characterize the role of complement activation under different pathological conditions, such as hypoxemia, ischemia and reperfusion, tissue damage, and polymicrobial invasion. Screening of the complement status and function is, however, strongly dependent on the laboratory-specific techniques being used to sample and measure complement, making it difficult to compare the results found in different laboratories. Therefore, we evaluated complement function by measuring complement hemolytic activity $(\mathrm{CH} 50)$ in various animal models of isolated ischemia reperfusion (I/R: kidney, liver, gut), hemorrhagic traumatic shock (HTS), endotoxic shock (LPS), and sepsis (CLP). Complement activation was less pronounced in isolated models of ischemia and reperfusion, whereas a strong complement response was observed early after HTS, CLP, and LPS. In summary, CH50 is a well-established, quick, and cost-effective screening method of complement function. However, because we obtained different results in clinically relevant animal models, further differentiation using specific complement factor analysis is necessary.
\end{abstract}

Keywords: CH50, complement, hemorrhagic shock, inflammation, ischemia/reperfusion, sepsis

\section{Introduction}

Recently, the complement system has regained scientific interest. In addition to the well-known vital complement functions in pathogen sensing, opsonization, and clearance, ${ }^{1}$ a second side of the complement system emerged. Upon excessive activation and depletion, the complement system may also exert harmful effects to host tissue. In various sepsis models, the complement system appears to be excessively stimulated, leading to massive generation of inflammatory mediators and systemic inflammatory response syndrome (SIRS). ${ }^{2-5}$ Particularly, the anaphylatoxins C3a, C5a, and membrane attack complex (MAC) may lead to molecular, cellular, and organ disturbances. ${ }^{6}$

In recent studies, we observed an association between the coagulation system with complement as a "new activation pathway" which appears to be involved in sepsis or multiple injury. ${ }^{7}$ In experimental and clinical settings involving severe tissue trauma, early excessive activation of complement has been detected. ${ }^{8,9}$ Ganter et al recently reported that complement activation early after major trauma is correlated with clinical outcome. ${ }^{9}$ Our studies examining blunt thoracic trauma models demonstrated some harmful effects of the complement activation product C5a in the local and systemic immune response, which were ameliorated through application of anti-C5a antibodies. ${ }^{8}$ Overall, complement activation appears to be involved in 
multiple diseases. However, its impact on various underlying pathophysiological conditions such as hypoxemia, ischemia and reperfusion, tissue damage, and polymicrobial invasion are not clearly understood.

Screening of complement status and function is dependent on the laboratory-specific techniques being used to sample and measure complement. Techniques for determining complement activity were first described as early as 1941 by Rutstein and Walker. ${ }^{10}$ Two decades later, Mayr was the first to describe a method for measuring complement activity, defined as the serum titer at which 50\% sensitized red blood cell hemolysis occurs. ${ }^{11}$

The CH50 assay is primarily employed as a screening method, focusing on the classical pathway for overall functionality of complement components 1-9 to determine significant complement activation, depletion, and complement defects. Although various known complement activation pathways appear to be differentially involved based on the underlying inflammatory response model, the CH50 assay remains an important initial analysis tool because of its relatively simple handling, validity, and cost-effectiveness. After initial assessment using classical CH50 analysis, more distinct methods are necessary to define the specific contribution and impact of other canonical (alternative, mannosebinding lectin) and non-canonical (thrombin, exogenous protease) pathways. Despite various laboratory modifications and availability of newer, ELISA-based and more automated assays, the CH50 assay is still broadly used. ${ }^{12}$ Its interpretation and intergroup comparability is particularly challenging, primarily due to the numerous existing laboratory-specific modifications of the original protocol. ${ }^{11}$

Therefore, we characterized the impact of classical complement activation in various clinically relevant experimental conditions using a uniform CH50 assay allowing estimation of the amount of classical activation between different experimental models.

Our results from this comparable study provide insight for further research examining complement monitoring and therapeutic modulation of the complement system.

\section{Materials and methods $\mathrm{CH} 50$-assay}

To sensitize sheep erythrocytes, sheep red cells (Colorado Serum Company, Denver, CO, USA) were washed 3 times using Tris-buffered saline, $\mathrm{pH} 7.35$ (TBS) and centrifuged at $1000 \times g$ for $5 \mathrm{~min}$ at $4^{\circ} \mathrm{C}$. Total erythrocyte volume was determined and the cells were diluted 20-fold with TBS. Cell lysis

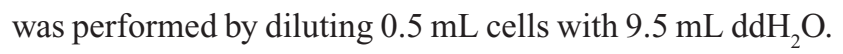

Optical density was measured and targeted between 497 and $505 \mathrm{~nm}$.

Serial dilutions from 1:2 through 1:4096 were prepared. First, $500 \mu \mathrm{L}$ TBS was added to all tubes. An additional $500 \mu \mathrm{L}$ hemolysin was added to the 1:2 tube. An ascending dilution series was created by transferring $500 \mu \mathrm{L}$ of each dilution. Next, $500 \mu \mathrm{L}$ of the cell suspension was added to each tube. Tubes were then incubated for $10 \mathrm{~min}$ at room temperature $(\mathrm{RT})$ and centrifuged at $1000 \times g$ for $5 \mathrm{~min}$ at $4^{\circ} \mathrm{C}$. The first hemolysin dilution in which no or very little agglutination occurred was considered to be the optimal dilution of hemolysin. Based on the optimal dilution (eg, 1:1024), hemolysin (eg, $10 \mu \mathrm{L}$ ) was diluted with TBS (eg, 10:1024 mL) and an equal part of the cell suspension (eg, 10:034 mL) was added. The solution was gently mixed and stored on ice.

Tubes for the CH50 dilution series (1:20-1:480) were then prepared. First, $1 \mathrm{~mL}$ TBS was added to all tubes, except the $1: 20(1900 \mu \mathrm{L})$ and the 1:30 tube $(1930 \mu \mathrm{L})$. As a control, $1.25 \mathrm{~mL}$ ddH $_{2} \mathrm{O}$ was added to 2 tubes for $50 \%$ lysis, $1 \mathrm{~mL}$ $\mathrm{ddH}_{2} \mathrm{O}$ was added to 2 tubes for $100 \%$ lysis, and TBS was added to 2 tubes for $0 \%$ lysis.

Next, $100 \mu \mathrm{L}$ of serum was added to the 1:40 tube and $66.6 \mu \mathrm{L}$ serum to the $1: 30$ tube. Serial dilutions were prepared by transferring $1 \mathrm{~mL}$ from the 1:20 through the 1:320 tubes and $1 \mathrm{~mL}$ from 1:30 through the 1:480 tubes. A total of $1 \mathrm{~mL}$ from the final 1:320 as and 1:480 dilutions were discarded. Sensitized sheep erythrocytes $(0.5 \mathrm{~mL})$ were added to each tube except for the $50 \%$ lysis control tube $(0.25 \mathrm{~mL})$, and the tubes were incubated for $60 \mathrm{~min}$ at $37^{\circ} \mathrm{C}$ in a shaking water bath.

The complement reaction was stopped using $1 \mathrm{~mL}$ of ice-cold TBS (containing $0.05 \%$ gelatin), followed by centrifugation $(2.500 \times g, 5 \mathrm{~min})$. Absorbance of the supernatant fluid was measured at $541 \mathrm{~nm}$, and the serum concentration that induced 50\% hemolysis (CH50) was determined.

\section{Animal models}

The experimental protocols of hemorrhagic shock, endotoxin shock, CLP-sepsis, and ischemia and reperfusion, were approved by the Animal Protocol Review Board of the city government of Vienna, Austria. Protocols were in accordance with the guidelines for the Care and Use of Laboratory Animals as defined by the National Institutes of Health. As an inter-group control for the animal studies, healthy untreated rats were anaesthetized and blood samples were obtained. For each animal model, blood samples obtained before beginning the experiment (baseline) served as intra-group controls. 


\section{Hemorrhagic shock}

The experiment was performed using male Sprague-Dawley rats $(\mathrm{n}=3$; 400-440 g; Animal Research Laboratories, Himberg, Austria). Anesthesia was induced by intramuscular injection of $112 \mathrm{mg} / \mathrm{kg}$ ketamine and $10 \mathrm{mg} / \mathrm{kg}$ xylazine and maintained by spontaneous respiration of $0.5 \%$ isoflurane. The right femoral artery was cannulated using a polyethylene catheter (PE-50; Fresenius, Bad Homburg, Germany) and connected to a blood pressure monitor (Cardiosys; Experimetria Biomedical Research, Budapest, Hungary). Rats were positioned and kept on a temperature-controlled surgical board $\left(36^{\circ} \mathrm{C}-37^{\circ} \mathrm{C}\right)$ for the duration of the experiment. Hemorrhage was induced by blood withdrawal via a catheter placed in the femoral artery until a mean arterial pressure (MAP) of $30-35 \mathrm{mmHg}$ was reached. This pressure was maintained for $2 \mathrm{~h}$ until the onset of decompensation, a state characterized by irreversible blood pressure collapse that can be prevented only by mandatory and repeated fluid infusion. At this point, the animals received a bolus dose of $4 \mathrm{~mL} / \mathrm{kg}$ bodyweight of Ringer solution. MAP was maintained at $40-45 \mathrm{mmHg}$ for $40 \mathrm{~min}$ by infusion of Ringer solution at a rate of $60 \mathrm{~mL} / \mathrm{kg} / \mathrm{h}$. Pilot experiments revealed that these rates were required to maintain MAP values within the $40-45 \mathrm{mmHg}$ target range in these experimental groups. After 40 min of permissive hypotension, rats were fully resuscitated to baseline blood pressure using Ringer solution, which required a volume of 2 times the shed blood volume as well as shed blood. Heparinized (10 IU/mL) shed blood used for resuscitation was filtered through $5-\mu \mathrm{m}$ membrane filters (Sterifix, B Braun Melsungen, Melsungen, Germany) to minimize the risk of thrombosis. Arterial Blood samples $(1 \mathrm{~mL})$ for $\mathrm{CH} 50$ analysis were drawn before shock (baseline), 30 min after shock induction, at the end of the permissive hypotensive stage (end of low flow), and $3 \mathrm{~h}$ after complete resuscitation with Ringer solution and shed blood (end of observation). The experiment was terminated $3 \mathrm{~h}$ after resuscitation using an overdose of pentobarbital sodium.

\section{Ischemia and reperfusion}

Male Sprague-Dawley rats (total number $\mathrm{n}=11 ; 400-440 \mathrm{~g}$ ) were used. Anesthesia was induced using ketamine hydrochloride administered intraperitoneally $(100 \mathrm{mg} / \mathrm{kg}$; Parke-Davis, Morris Plains, NJ, USA) and spontaneous respiration was maintained with $0.5 \%$ isoflurane. A polyethylene catheter (PE50; Fresenius, Bad Homburg, Germany) was inserted into the left femoral artery under aseptic conditions and connected to a blood pressure monitor (Cardiosys Experimentria, Budapest, Hungary) for continuous MAP monitoring during anesthesia. A second catheter (PE-50) was inserted into the right jugular vein for resuscitation. Arterial blood samples $(0.5 \mathrm{~mL})$ for CH50 analysis were drawn and replaced by saline $(1 \mathrm{~mL})$ before the experiment (baseline) and $5 \mathrm{~min}$ before reperfusion as well as 5 and 120 min post ischemia (gut, liver, and kidney I/R). Laparotomy was closed using 3-0 silk sutures and resuscitation was carried out by administering $15 \mathrm{~mL} / \mathrm{kg}$ of Ringers' solution per hour for $3 \mathrm{~h}$, commencing at reperfusion onset. ${ }^{13}$ After the final blood sampling, the animals were killed using an overdose of pentobarbital sodium.

Liver ischemia and reperfusion was performed in rats $(\mathrm{n}=3)$ with slight modification of previously described techniques. ${ }^{14}$ The liver was exposed using midline laparotomy. Silk ligatures were placed around the right and left branches of the portal vein and hepatic artery. After a 15-min stabilization period, complete ischemia of the median and left liver lobes was induced by occluding the left branch of the portal vein and hepatic artery for $60 \mathrm{~min}$. The right liver lobe was perfused to prevent intestinal congestion. During liver ischemia, the abdomen was covered with saline-moistened gauze and plastic wrap to prevent dehydration. After $60 \mathrm{~min}$ of liver ischemia, ligatures were removed.

For intestinal ischemia and reperfusion, rat guts $(n=4)$ were exposed using midline laparotomy. The superior mesenteric artery was isolated from the surrounding connective tissue at its aortic origin. After a 15-min stabilization period, superior mesenteric artery occlusion (SMAO) was performed by placing a silk ligature around the mesenteric root. The gut remained pale during occlusion and no venous stasis or congestion occurred. During gut ischemia, the abdomen was covered with salinemoistened gauze and plastic wrap to prevent dehydration. After $60 \mathrm{~min}$ of ischemia, the ligation was removed from the mesenteric root to allow reperfusion. Reperfusion was confirmed by the return of pulsations to the mesenteric vascular arcade.

For kidney ischemia, a midline incision was made in rats $(n=4)$ to gain access to the kidneys. After a 15-min stabilization period, afferent blood vessels to both the left and the right kidney were ligated at their respective points of entry into the kidney. During kidney ischemia, the abdomen was covered with saline-moistened gauze and plastic wrap to prevent dehydration. After $60 \mathrm{~min}$ of kidney ischemia, ligatures were removed from afferent vessels to the left and right kidney to allow reperfusion.

\section{Endotoxin shock model (LPS)}

The experiment was performed as previously described. ${ }^{15,16}$ Briefly, male Sprague-Dawley rats $(\mathrm{n}=3 ; 240-260 \mathrm{~g})$ were used. Endotoxin (lipopolysaccharide = LPS) from E. coli O26:B6 (Difco) was dissolved in $0.9 \%(\mathrm{w} / \mathrm{v}) \mathrm{NaCl}$ and 
injected intraperitoneally $(10 \mathrm{mg} / \mathrm{kg})$. Blood samples for CH50 assay were taken 1,4 , and $8 \mathrm{~h}$ after endotoxin administration by orbital puncturing under isoflurane inhalation anesthesia. After the last blood sampling, animals were killed using an overdose of pentobarbital sodium.

\section{Experimental sepsis induced by cecal ligation and puncture (CLP)}

Experimental CLP sepsis has been described in detail elsewhere. ${ }^{17}$ Briefly, male Sprague-Dawley rats $(\mathrm{n}=5$; 240-260 g) were anesthetized by intraperitoneal administration of ketamine hydrochloride $(100 \mathrm{mg} / \mathrm{kg})$ and spontaneous respiration was maintained using $0.5 \%$ isoflurane. After a midline incision, the cecum was tightly ligated below the ileocecal valve, carefully avoiding bowel obstruction. The cecum was then punctured through using a 21-gauge needle. After repositioning of the bowel, the abdominal incision was closed in layers (4-0 silk suture and skin clips; Ethicon). Arterial blood samples from the femoral catheter $(0.5 \mathrm{~mL})$ for the CH50 assay were taken before and 3, 7, 24, and $48 \mathrm{~h}$ post CLP induction by orbital puncturing under isoflurane inhalation anesthesia and immediately replaced by subcutaneous saline infusion. After the last blood sampling, animals were killed using an overdose of pentobarbital sodium.

\section{Results}

\section{Ischemia and reperfusion (I/R)}

Renal I/R

In the renal I/R model, CH50 determination revealed no significant changes between control and I/R groups, indicating no significant classical complement activation or consumption of complement factors 1-9 occurred in this model (Figures 1 and 2A).

\section{Liver I/R}

In comparison to the unaltered complement function in renal ischemia and reperfusion, the liver I/R model revealed some changes in CH50. Five minutes before the end of ischemia, CH50 decreased by $12 \%$ compared to control values. Throughout the experiment, CH50 decreased to 48\% (5 min after end of I/R) and 72\% (120 min after end of I/R) compared to values of the control group (Figures 1 and $2 \mathrm{~B}$ ).

\section{Intestinal I/R}

In the intestinal ischemia model, only minor changes in CH50 were observed. During the time course of the experiment, $\mathrm{CH} 50$ increased by $2 \%$ ( $5 \mathrm{~min}$ post I/R) and decreased by $14 \%$ (120 min post I/R) compared to baseline values (Figures 1 and 2C).

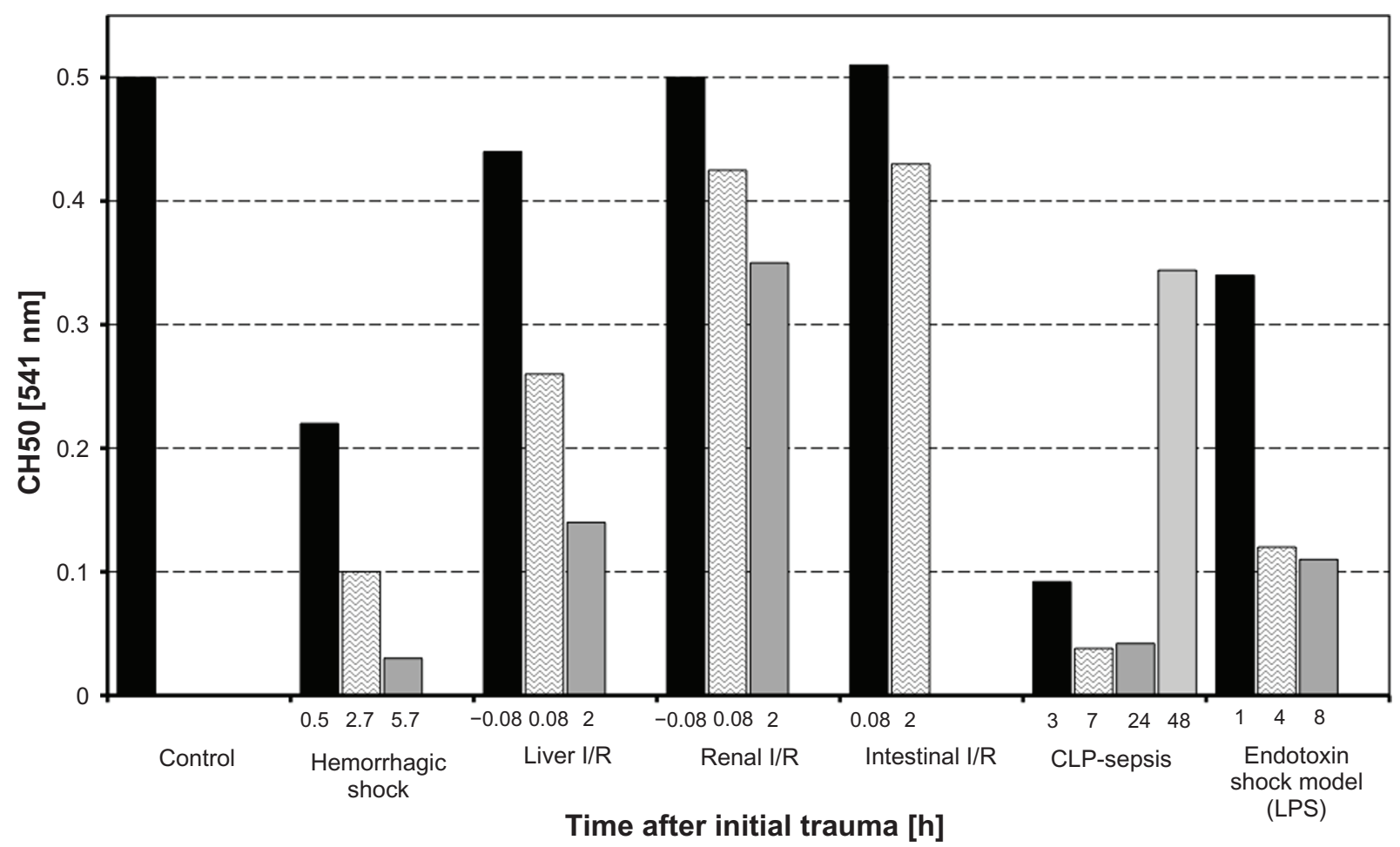

Figure I Serum hemolytic complement activity $(\mathrm{CH} 50)$ of rats undergoing various clinically relevant experimental procedures. Displayed are mean values of $\mathrm{CH} 50$ data during the time course of the experiments compared to the control.

Abbreviations: CLP, cecal ligation and puncture; I/R, ischemia/reperfusion; LPS, lipopolysaccharide. 

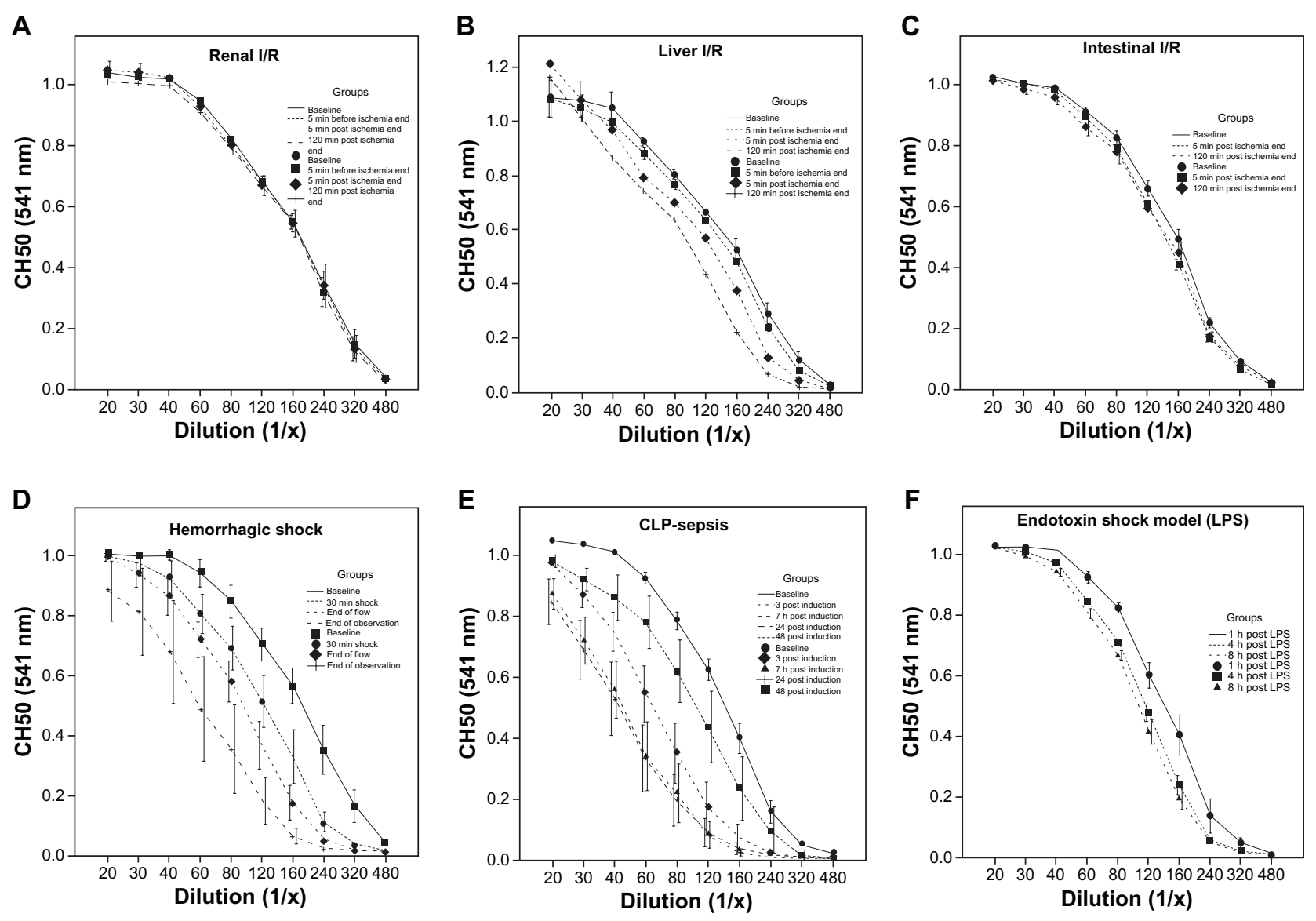

Figure 2 Time courses of serum hemolytic complement activity $(\mathrm{CH} 50)$ of rats subjected to various diseases. Note: Displayed are means $+/-$ SEM.

Abbreviations: CLP, cecal ligation and puncture; I/R, ischemia/reperfusion; LPS, lipopolysaccharide.

\section{Hemorrhagic shock}

In striking contrast to the ischemia and reperfusion models, significant complement activation was observed in the hemorrhagic shock model. Early after induction of hemorrhagic shock (30 min after injury), CH50 dropped to $44 \%$ compared to the values of the control littermates. At the end of the low flow period, CH50 was only $20 \%$ of the control value. At the end of observation, $\mathrm{CH} 50$ was minimal, with a reduction of nearly $94 \%$ compared to control animals (Figures 1 and 2D). The difference between all time points reached significance.

\section{CLP-sepsis (cecal ligation and puncture)}

In the well-established model of CLP-induced sepsis, the extent of complement activation was comparable to that during hemorrhagic shock. Early after induction of sepsis $(3 \mathrm{~h}$ after CLP), CH50 dropped significantly to $18 \%$ and further declined to $8 \%$ (after $7 \mathrm{~h}$ and $24 \mathrm{~h}$ ) compared to baseline values. At the last blood sampling time point, which was $48 \mathrm{~h}$ after CLP, CH50 had recovered to approximately $70 \%$ of the control values (Figures 1 and 2E).

\section{Endotoxin shock model (LPS)}

In an endotoxin shock model induced by intraperitoneal LPSinjection, activation of the complement system as assessed by reduced $\mathrm{CH} 50$ values was remarkable. However, activation did not occur to the same extent observed in the CLP-sepsis or hemorrhagic shock models. CH50 dropped to $68 \%$ after $1 \mathrm{~h}$ and decreased additionally after $4 \mathrm{~h}$, reaching a plateau of approximately $20 \%$ after the last blood sampling at $8 \mathrm{~h}$ post LPS (Figures 1 and 2F).

\section{Discussion}

Studies focusing on the complement system and its potential role in the pathogenesis of inflammatory response for surgically relevant diseases have been widely performed and have employed various animal models. ${ }^{8,10,17-27}$ However, the ability to compare values found in these studies is difficult since most experimental studies involve different study designs and varying methods for assessing complement activation.

Our study provides comparable data for complement activation/depletion for various rodent models postulated to involve complement and to mimic clinical relevant surgical diseases. 
In ischemia/reperfusion experiments, conflicting results were observed between our results and those of other reports. After I/R of the kidneys, CH50 values were nearly unchanged for the entire observation period. This was somewhat unexpected, as it had been proposed by previous existing studies that kidney ischemia and reperfusion results in enhanced tubular deposition rates of $\mathrm{C} 3$ and MAC, and that an antibody treatment against $\mathrm{C} 5^{28}$ or the $\mathrm{C} 5$ a receptor ${ }^{29}$ significantly protects against kidney dysfunction. However, since systemic complement activation was not observed in those studies, it can be speculated that kidney I/R primarily leads to local complement activation without a systemic effect. Notably, CH50 predominantly involves classical complement pathway activation. Thus, in the unlikely case of exclusive alternative pathway or "extrinsic protease pathway" ${ }^{\prime 30}$ activation in kidney I/R injury, would not be observed. Recently, a new ELISA-based complement analyzing kit has been developed, ${ }^{12}$ which may differentiate between all three established pathways in one setting. Unfortunately, these tests are limited to humans and pigs and are not applicable to rodents.

In contrast to kidney $\mathrm{I} / \mathrm{R}$, a remarkable decline of CH50 values was observed in liver $\mathrm{I} / \mathrm{R}$. Only $5 \mathrm{~min}$ after ischemia, CH50 fell by nearly $50 \%$ with a nadir of $72 \%$ after $2 \mathrm{~h}$ versus baseline levels. However, CH50-sensitive activation in this experimental setting is relatively modest when compared to the results after hemorrhage or during CLP-sepsis. One possible explanation for this could be the strong compensational and regenerative capacity of the liver after applied I/R stress. Contrary to the paradigm that complement activation products cause host tissue damage, it has recently been shown that $\mathrm{C} 3 \mathrm{a}$ and $\mathrm{C} 5 \mathrm{a}$ are essential factors for liver regeneration, with $\mathrm{C} 3 \mathrm{a}$ and $\mathrm{C} 5 \mathrm{a}$ diminishing the rate of liver apoptosis and acting as pro-survival factors. ${ }^{31}$

In the model of $\mathrm{I} / \mathrm{R}$ of the gut, a modest $\mathrm{CH} 50$ response was detected. A maximal decrease of $\mathrm{CH} 50$ of approximately $10 \%$ occurred $120 \mathrm{~min}$ post-I/R. It must be emphasized that changes in $\mathrm{CH} 50$ of approximately $10 \%$ reflect a systemic activation. Therefore, the present findings seem to be in agreement with some reports showing that gut I/R induces not only a local but also a systemic inflammatory response with C5a-dependent remote tissue injuries. ${ }^{32}$

In contrast to the models of local I/R, hemorrhagic shockinduced systemic hypotension was associated with robust changes (up to 94\%) in CH50, indicating massive complement activation and depletion. These results are consistent with the findings of Younger et al who also described massive consumption of complement products with serum hemolytic activity reduction by $33 \% 50$ min after induction of hemorrhagic shock in rodents. ${ }^{33}$ The $\mathrm{CH} 50$ reduction in our experiments exceeded that of Younger et al, strongly supporting their findings of complement-induced progressive hypotension and contribution to metabolic acidosis after resuscitation procedures. ${ }^{33} \mathrm{CH} 50$ values at the end of the experiment could not have resulted from dilution because significant changes were observed at the early blood-drawings with no or minimal blood dilution. Hemorrhagic shock is associated with high mortality, ${ }^{34}$ and understanding the pathophysiology will advance the development of treatment, particularly specific immunomodulatory drugs. Whether specific immune modulation of complement is beneficial during hemorrhagic shock remains to be elucidated.

For two well-known models of endotoxemia and sepsis, a remarkable right shift of $\mathrm{CH} 50$ curves compared to control groups was observed. A maximum decrease in $\mathrm{CH} 50$ was observed $7 \mathrm{~h}$ after CLP-sepsis (92\% reduction) and $8 \mathrm{~h}$ after LPS challenge (78\% reduction). Notably, in the CLPsepsis model, CH50 values increased after $48 \mathrm{~h}$ to values approximately $30 \%$ below baseline, indicating some recovery of complement function in surviving animals. Systemic inflammation and complement activation in CLP- and LPSmodels has been extensively examined. The possibility of therapeutic complement modulation was successfully demonstrated by protection of septic animals treated with C5a antibodies ${ }^{20}$ or C5a receptor antagonists. ${ }^{21}$ Flierl et al recently described CLP-sepsis systemic complement activation with similar CH50 values..$^{35}$ Our results corroborate the strong pathogenetic role of complement activation during sepsis. ${ }^{20}$ Both models of endotoxemia and sepsis induced massive complement activation, but the decline in $\mathrm{CH} 50$ was more distinct in the CLP-model than in the LPS-model. CLP mimics the clinical conditions of sepsis much more closely than LPS-injection, primarily because LPS-intoxication can result in the LPS-model. ${ }^{36}$

\section{Conclusion}

We compared classical complement activation in various clinically relevant rodent models which have been proposed to be highly complement-dependent. In ischemia and reperfusion injuries, an overall (classical) complement activation appears to be relatively limited, whereas a strong complement response is evident early after CLP-induced sepsis and during hemorrhagic/traumatic shock. Although $\mathrm{CH} 50$ assays are quick and cost-efficient, they are only a general screening tool and further, more specific differentiation is required. Due to the small number of animals and the basic screening 
method for complement activation, our data provides a global estimation of complement activation in the described disease conditions and is the first inter-group comparison between various clinical relevant animal models.

Subsequent translational studies are needed to verify the role of complement and its therapeutic potential in tissue hypoxia, infection, and trauma.

\section{Acknowledgments}

We thank Sonja Albers and Barbara Acker for excellent experimental assistance. This study was partially supported by $\mathrm{KFO} 200$ (Hu 823/3-1).

\section{Disclosure}

The authors report no conflicts of interest.

\section{References}

1. Barrington R, Zhang M, Fischer M, Carroll MC. The role of complement in inflammation and adaptive immunity. Immunol Rev. 2001;180:5-15.

2. Ward PA. The dark side of C5a in sepsis. Nat Rev Immunol. 2004;4(2):133-142.

3. Gerard C. Complement C5a in the sepsis syndrome - too much of a good thing? N Engl J Med. 2003;348(2):167-169.

4. Guo RF, Ward PA. Role of C5a in inflammatory responses. Annu Rev Immunol. 2005;23:821-852.

5. Rittirsch D, Flierl MA, Ward PA. Harmful molecular mechanisms in sepsis. Nat Rev Immunol. 2008;8(10):776-787.

6. Riedemann NC, Guo RF, Laudes IJ, et al. C5a receptor and thymocyte apoptosis in sepsis. Faseb J. 2002;16(8):887-888.

7. Huber-Lang M, Sarma JV, Zetoune FS, et al. Generation of C5a in the absence of C3: a new complement activation pathway. Nat Med. 2006;12(6):682-687.

8. Flierl MA, Perl M, Rittirsch D, et al. The role of C5a in the innate immune response after experimental blunt chest trauma. Shock. 2008;29(1):25-31.

9. Ganter MT, Brohi K, Cohen MJ, et al. Role of the alternative pathway in the early complement activation following major trauma. Shock. 2007;28(1):29-34.

10. Rutstein DD, Walker WH. Complement Activity in Pneumonia. J Clin Invest. 1942;21(3):347-352.

11. Mayer MM. Complement and complement fixation. In: Kabat EA, editor. Experimental Immunochemistry. Springfield, IL: Thomas; 1961: 133-240.

12. Salvesen B, Mollnes TE. Pathway-specific complement activity in pigs evaluated with a human functional complement assay. Mol Immunol. 2009;46(8-9):1620-1625.

13. Pelinka LE, Harada N, Szalay L, Jafarmadar M, Redl H, Bahrami S. Release of S100B differs during ischemia and reperfusion of the liver, the gut, and the kidney in rats. Shock. 2004;21(1):72-76.

14. Harada N, Okajima K, Kushimoto S. Gabexate mesilate, a synthetic protease inhibitor, reduces ischemia/reperfusion injury of rat liver by inhibiting leukocyte activation. Crit Care Med. 1999;27(9):1958-1964.

15. Drouin SM, Kildsgaard J, Haviland J, et al. Expression of the complement anaphylatoxin $\mathrm{C} 3 \mathrm{a}$ and $\mathrm{C} 5 \mathrm{a}$ receptors on bronchial epithelial and smooth muscle cells in models of sepsis and asthma. J Immunol. 2001;166(3):2025-2032.

16. Werner ER, Bahrami S, Heller R, Werner-Felmayer G. Bacterial lipopolysaccharide down-regulates expression of GTP cyclohydrolase I feedback regulatory protein. J Biol Chem. 2002;277(12):10129-10133.
17. Baker CC, Chaudry IH, Gaines HO, Baue AE. Evaluation of factors affecting mortality rate after sepsis in a murine cecal ligation and puncture model. Surgery. 1983;94(2):331-335.

18. Bahrami S, Zimmermann K, Szelényi Z, et al. Small-volume fluid resuscitation with hypertonic saline prevents inflammation but not mortality in a rat model of hemorrhagic shock. Shock. 2006;25(3): 283-289.

19. Bumann M, Henke T, Gerngross H, Claes L, Augat P. Influence of haemorrhagic shock on fracture healing. Langenbecks Arch Surg. 2003;388(5):331-338.

20. Czermak BJ, Sarma V, Pierson CL, et al. Protective effects of C5a blockade in sepsis. Nat Med. 1999;5(7):788-792.

21. Huber-Lang MS, Riedeman NC, Sarma JV, et al. Protection of innate immunity by C5aR antagonist in septic mice. Faseb J. 2002; 16(12):1567-1574.

22. Kyriakides C, Austen W Jr, Wang Y, et al. Skeletal muscle reperfusion injury is mediated by neutrophils and the complement membrane attack complex. The Am J Physiol. 1999;277(6 Pt 1): C1263-C1268.

23. Leinhase I, Holers VM, Thurman JM, et al. Reduced neuronal cell death after experimental brain injury in mice lacking a functional alternative pathway of complement activation. BMC Neurosci. 2006;7:55.

24. Stahl GL, Xu Y, Hao L, et al. Role for the alternative complement pathway in ischemia/reperfusion injury. Am J Pathol. 2003;162(2): 449-455.

25. Woodruff TM, Arumugam TV, Shiels IA, Reid RC, Fairlie DP, Taylor SM. Protective effects of a potent C5a receptor antagonist on experimental acute limb ischemia-reperfusion in rats. J Surg Res. 2004;116(1):81-90.

26. Bengtsson A, Redl H, Schlag G, Högåsen K, Götze O, Mollnes TE. Anti-TNF treatment of baboons with sepsis reduces TNF-alpha, IL-6 and IL-8, but not the degree of complement activation. Scand J Immunol. 1998;48(5):509-514.

27. Mollnes TE, Redl H, Høgåsen K, et al. Complement activation in septic baboons detected by neoepitope-specific assays for $\mathrm{C} 3 \mathrm{~b} / \mathrm{iC} 3 \mathrm{~b} / \mathrm{C} 3 \mathrm{c}, \mathrm{C} 5 \mathrm{a}$ and the terminal C5b-9 complement complex (TCC). Clin Exp Immunol. 1993;91(2):295-300.

28. De Vries B, Matthijsen RA, Wolfs TG, Van Bijnen AA, Heeringa P, Buurman WA. Inhibition of complement factor C5 protects against renal ischemia-reperfusion injury: inhibition of late apoptosis and inflammation. Transplantation. 2003;75(3):375-382.

29. Arumugam TV, Shiels IA, Strachan AJ, Abbenante G, Fairlie DP, Taylor SM. A small molecule C5a receptor antagonist protects kidneys from ischemia/reperfusion injury in rats. Kidney Int. 2003;63(1): 134-142.

30. Ricklin D, Lambris JD. Complement-targeted therapeutics. Nat Biotechnol. 2007;25(11):1265-1275.

31. Markiewski MM, DeAngelis RA, Strey CW, et al. The regulation of liver cell survival by complement. J Immunol. 2009;182(9):5412-5418.

32. Zhao H, Montalto MC, Pfeiffer KJ, Hao L, Stahl GL. Murine model of gastrointestinal ischemia associated with complement-dependent injury. J Appl Physiol. 2002;93(1):338-345.

33. Younger JG, Sasaki N, Waite MD, et al. Detrimental effects of complement activation in hemorrhagic shock. J Appl Physiol. 2001;90(2): 441-446.

34. Curry N, Hopewell S, Doree C, Hyde C, Brohi K, Stanworth S. The acute management of trauma hemorrhage: a systematic review of randomized controlled trials. Crit Care. 2011;15(2):R92.

35. Flierl MA, Rittirsch D, Nadeau BA, et al. Functions of the complement components C3 and C5 during sepsis. Faseb J. 2008;22(10): 3483-3490.

36. Remick DG, Newcomb DE, Bolgos GL, Call DR. Comparison of the mortality and inflammatory response of two models of sepsis: lipopolysaccharide vs cecal ligation and puncture. Shock. 2000;13(2): 110-116. 
Journal of Inflammation Research

Dovepress

\section{Publish your work in this journal}

The Journal of Inflammation Research is an international, peer-reviewed open-access journal that welcomes laboratory and clinical findings on the molecular basis, cell biology and pharmacology of inflammation including original research, reviews, symposium reports, hypothesis formation and commentaries on: acute/chronic inflammation; mediators of inflamma-

tion; cellular processes; molecular mechanisms; pharmacology and novel anti-inflammatory drugs; clinical conditions involving inflammation. The manuscript management system is completely online and includes a very quick and fair peer-review system. Visit http://www.dovepress.com/ testimonials.php to read real quotes from published authors.

Submit your manuscript here: http://www.dovepress.com/journal-of-inflammation-research-journal 